\title{
Der Triumph der ökonomischen
} Medizin

Wo man hinhört, hört man Klagen drüber, was der muss ertragen, der bei seinen Leisten still und im Ernste bleiben will. Denn es wächst in ihm Empörung über seiner Arbeit Störung. Kürzlich hat der CEO dargelegt, er denke so: Weder sei es klug noch richtig, wenn man Ärzte hält für tüchtig, deren Leistung nicht gemessen täglich durch die Zählung dessen, was exakt sich zählen lasse, dass man ihren Wert erfasse.

Sprach: «Drum legen wir Gewicht sehr auf Ihren Fachbericht

für die Information

unserer ganzen Region.

Dies zeigt Ihre Presse-Kraft,

welche PR-Punkte schafft.

Schon für Sie im Sinn des Ganzen ist gebucht der Kurs BILANZEN.

Unsere Physio-Abteilung braucht viel höhere Auslastung, dies, indem Sie Wege finden, auch Gesunde anzubinden. Sehr erwünscht ist, wenn noch Zeit für Beratungstätigkeit bleibt in unsern Führungsgremien, selbst wenn hier nicht winken Prämien. Dieses AUF VEREINTEN WEGEN kommt dem Wir-Gefühl entgegen. Jährlich steigt die Punktzahl zwar, die fürs gleiche Honorar nach betrieblichen Beschlüssen Sie zusammentragen müssen. Doch gelingt es so, Vertrauen auf den Punkten aufzubauen, und es spukt nicht mehr herein der Gefühle schale Schein. Auch ersetzt der Punktepegel elegant die Standesregel, insbesondere handelt es sich um, was Hippokrates mit dem Eide einst gelobte und erfolgreich er erprobte, doch das stört, bei aller Achtung für die ethische Betrachtung, unsere Kosteneffizienz der Privatteil-Konkurrenz und es brächte Ihnen Frust durch enormen Punktverlust, wäre wider das Verhalten, Abklärung so zu gestalten, dass der Kunde nicht muss warten, bis wir neuste Technik starten, sondern rasch und wenn vonnöten nochmals wird hereingebeten, dass das Wohl-Tun er verspürt, welches man signalisiert, aber er bei diesen Dingen nicht vermeint, man möcht ihn zwingen, sondern schliesst, dass die Beschwerden endlich ernst genommen werden. Unserseits wird immer alles abgerechnet, dass des Falles ökonomisches Gewicht unserem Optimum entspricht. Und das geht nur, wenn das Denken Algorithmen trefflich lenken, warnen, dass beim Kranken-Heilen man nicht redend soll verweilen, weil es unsern Cash-Flow stört, wenn zu lange zu man hört.
Dass nun diesen Kodex stützen Ärzte, Pflege und benützen und dadurch die Klinik prägen, ist für den Betrieb ein Segen. Sprache wird sogar durchdrungen, dadurch, was uns schon gelungen mit der ÖKOMEDIZIN,

die nun immer mehr wird blüh'n.

Dass nicht droh'n geldwerte Fehler, gibt's den KLINIK-KODEX-ZÄHLER, der berechnet instantan, welcher Teil des, was getan, als Gewinn für unser Haus stündlich, täglich springt heraus. Jedermann kann sein Verhalten dementsprechend jetzt gestalten und auch individuell

seinen Bonus auf der Stell,

was auch klar erfüllt den Sinn unseres Leitmotivs WIN-WIN.»

Prof. em. Dr. med. Max Stäubli, Ebmatingen

Ein Gedicht in Anlehnung an die satirisch mahnende Komödie Knock oder Der Triumph der Medizin [1] von Jules Romains und zwei in der Schweizerischen Ärztezeitung erschienene Artikel zum Thema Gesundheitsökonomie $[2,3]$.

\section{Bildnachweis}

Grafphotogpaher | Dreamstime.com

\section{Literatur}

1 Romains J. Knock oder Der Triumph der Medizin Stuttgart: Philipp Reclam jun.; 1997.

2 Aujesky D, Capaul R. Gegen die zunehmende Ökonomisierung der Medizin. Schweiz Ärzteztg. 2021;102(27-28):911-2.

3 Capaul R, Brack T, Aujesky D. Medizin und Ökonomie. Schweiz Ärzteztg. 2020;101(44):1450. 